\section{Instrução aos autores da Revista Brasileira de Medicina de Família e Comunidade}

A Revista Brasileira de Medicina de Família e Comunidade (RBMFC) é uma publicação trimestral da Sociedade Brasileira de Medicina de Família e Comunidade, que tem por finalidades: sensibilizar profissionais e autoridades da área de saúde sobre a área de interesse da Medicina de Família e Comunidade; estimular e divulgar temas e pesquisas em Atenção Primária à Saúde (APS); possibilitar o intercâmbio entre academia, serviço e movimentos sociais organizados; promover a divulgação da abordagem interdisciplinar e servir como veículo de educação continuada e permanente no campo da Medicina de Família e Comunidade, tendo como eixo temático a APS.

Os trabalhos serão avaliados por editores do Con- selho Científico e Editorial, como também por pareceristas convidados ad hoc. O processo de avaliação por pares preserva a identidade dos autores e suas afiliações, sendo estas informadas ao Conselho Editorial somente na fase final de avaliação.

Todos os trabalhos deverão ser escritos em português, com exceção dos redigidos por autores estrangeiros não-residentes no Brasil, que poderão fazê-lo em inglês ou espanhol.

\section{Tipos de Trabalho}

A revista está estruturada com as seguintes seções:

Editorial

Artigos Originais

Artigos de Revisão

Diretrizes em Medicina de Família e Comunidade Ensaios
Relatos de Experiência

Resumos de Tese

Cartas ao Editor

O Editorial é de responsabilidade do editor da revista, podendo ser redigido por terceiros por solicitação dele.

A seção Artigos Originais é composta por artigos resultantes de pesquisa científica, apresentando dados originais de descobertas com relação a aspectos experimentais ou de observação, voltados para investigações qualitativas ou quantitativas em áreas de interesse da APS. Artigos originais são trabalhos que desenvolvem crítica e criação sobre a ciência, tecnologia e arte das ciências da saúde que contribuem para a evolução do conhecimento sobre o homem, a natureza e a inserção social e cultural. O texto - contendo introdução, material ou casuística, métodos, resultados, discussão e conclusão - deve ter até 25 laudas.

A seção Artigos de Revisão é composta por artigos nas áreas de Gerência, Clínica, Educação em Saúde. Os artigos de revisão são trabalhos que apresentam síntese atualizada do conhecimento disponível sobre matérias das ciências da saúde, buscando esclarecer, organizar, normalizar e simplificar abordagens dos vários problemas que afetam o conhecimento humano sobre o homem e a natureza e sua inserção social e cultural. Têm por objetivo resumir, analisar, avaliar ou sintetizar trabaIhos de investigação já publicados em revistas científicas e devem ter até 20 laudas, contendo introdução, desenvolvimento e conclusão.

A seção Diretrizes em MFC é composta por artigos estruturados dentro das normas da Associação Médica Brasileira para diretrizes clínicas, validados pela SBMFC. Sua confecção, sob orienta 
ção da Diretoria Científica da SBMFC, é uma proposta de organizar e referendar o trabalho dos MFC no Brasil.

A seção Ensaios visa à divulgação de artigos com as análise crítica sobre um tema específico relacionado à Medicina de Família e Comunidade e deve ser apresentada em uma média de 5 a 10 laudas.

A seção Relatos de Experiência é composta de artigos que relatam casos ou experiências os quais explorem um método ou problema por meio do exemplo. Os relatos de caso apresentam as características do indivíduo estudado - com indicação de sexo e idade, podendo este ser humano ou animal -, ressaltam sua importância na atuação prática e mostram caminhos, condutas e comportamentos para a solução do problema. Essa parte deve ocupar até 8 laudas, com a seguinte estrutura: introdução, desenvolvimento e conclusão.

A seção Resumos de Tese, que deve ter apenas 1 lauda, tem como proposta a divulgação da produção científica na temática do periódico. Nela, devem ser expostos resumos de dissertações de mestrado ou teses de doutoramento/livredocência defendidas e aprovadas em universidades brasileiras ou não. Os resumos deverão ser encaminhados com o título oficial da Tese, informando o título conquistado, o dia e o local da defesa. Devem ser informados, igualmente, o nome do Orientador e o local onde a tese está disponível para consulta.

Em Cartas ao Editor, opiniões de leitores e su- gestões sobre a revista são bem recebidas. As cartas, contendo comentários sobre material publicado, devem ter no máximo 2 laudas.

Os trabalhos a serem submetidos à apreci- ação do Conselho Científico deverão ser encaminhados por e-mail para a Secretaria da Sociedade Brasileira de Medicina de Família e Comunidade ou ao Editor da revista. O padrão de formatação exigido é Word for Windows - versão 6.0 ou superior -, página padrão A4, letra Arial (tamanho 11), espaçamento entre linhas 1,5 e numeração seqüencial em todas as páginas. As notas de rodapé devem ser limitadas ao máximo possível, assim como as tabelas e os quadros - que devem ser de compreensão independente do texto.

Os autores deverão informar seus nomes e ende- reços completos e quais organizações de fomento à pesquisa apoiaram os seus trabalhos, fornecendo inclusive o número de cadastro do projeto.

Os trabalhos que envolverem pesquisas com seres humanos deverão vir acompanhados da devida autorização do Comitê de Ética da Instituição.

Os trabalhos devem obedecer à seguinte seqüência de apresentação:

1. Título em português e também em inglês $\left.{ }^{*}\right)$.

2. Nome completo - nome(s) seguido(s) do(s) sobrenome(s) do(s) autor(es) - e, no rodapé, a indicação da Instituição a qual está vinculado, cargo e titulação.

3. Resumo do trabalho em português, no qual fiquem claros a síntese dos propósitos, os métodos empregados e as principais conclusões do trabalho.

4. Palavras-chave - mínimo de 3 e máximo de 5 palavras-chave ou descritores do conteúdo do trabalho, apresentados em português de acordo com o DeCS - Descritores em Ciências da Saúde da BIREME - Centro Latino Americano e do 
Caribe de Informação em Ciências da Saúde URL: <http://decs.bvs.br/>.

5. Abstract - versão do resumo em inglês $\left({ }^{*}\right)$.

6. Key words - palavras-chave em inglês, de acordo com DeCS $\left.{ }^{*}\right)$.

7. Artigo propriamente dito, de acordo com a estrutura recomendada para cada tipo de artigo, citada no item 2.

8. Figuras (gráficos, desenhos e tabelas) devem ser enviadas à parte, com indicação na margem do local de inserção no texto; as fotografias em preto e branco devem ser apresentadas em papel brilhante.

9. Referências: são de responsabilidade dos autores e deverão ser limitadas às citações do texto, além de numeradas segundo a ordem de referência, de acordo com as regras propostas pelo Comitê Internacional de Revistas Médicas (International Committee of Medical Journal Editors). Requisitos uniformes para manuscritos apresentados a periódicos biomédicos. Disponível em: <http://www.icmje.org>.

$\left({ }^{*}\right)$ A versão do título do trabalho, do resumo e das palavras-chave para o idioma inglês ficará a cargo da própria revista, salvo eventual decisão ao contrário em época futura que, se vier ao caso, será comunicada no Editorial da revista.

Exemplos:

\section{Periódico}

Valla VV. Educação popular e saúde diante das formas de se lidar com a saúde. Revista APS. 2000; (5): 46-53.

\section{Livro}

Birman J. Pensamento freudiano. Rio de Janeiro: Jorge Zahar; 1994. 204p.

\section{Capítulo de livro}

Vasconcelos EM. Atividades coletivas dentro do Centro de Saúde. In: Educação popular nos serviços de saúde. 3. ed. São Paulo: HUCITEC; 1997. p. 65-69.

\section{Dissertação}

Caldas CP. Memória dos velhos trabalhadores. [Dissertação]. Rio de Janeiro, Instituto de Medicina Social, Universidade do Estado do Rio de Janeiro; 1993.

\section{Evento}

Mauad NM, Campos EM. Avaliação da implantação das ações de assistência integral à saúde da mulher no PIES/UFJF; $6^{\circ}$ Congresso Brasileiro de Saúde Coletiva; 2000, Salvador. Salvador: Associação Brasileira de Pós-graduação em Saúde Coletiva; 2000. p.328.

\section{Documento eletrônico}

Civitas. Coordenação de Simão Pedro P. Marinho. Desenvolvido pela Pontifícia Universidade Católica de Minas Gerais, 1995-1998.

Apresenta textos sobre urbanismo e desenvolvimento de cidades. Disponível em:

www.gcsnet.com.br/oamis/civitas.

Acesso em: 27 nov. 1998.

Fluxo dos trabalhos submetidos à publicação.

Os artigos são de total e exclusiva responsabilidade dos autores. 
Avaliação por pares: os artigos recebidos são protocolados na secretaria da revista e encaminhados tanto ao editor geral quanto aos editores associados, para a triagem, a avaliação preliminar e a posterior distribuição ao Conselho Editorial e Científico, em conformidade com as áreas de atuação e especialização dos membros, bem como o assunto tratado no artigo. Todos os textos são submetidos à avaliação de dois consultores provenientes de instituição diferente daquela do(s) autor(es) -, em um processo duplo cego, que os analisam em relação aos seguintes aspectos: adequação do título ao conteúdo; estrutura da publicação; clareza e pertinência dos objetivos; metodologia; informações inteligíveis; citações e referências adequadas às normas técnicas adotadas pela revista e pertinência à linha editorial da publicação. Os consultores preenchem o formulário de parecer, aceitando, recusando ou recomendando correções e/ou adequações necessárias. Nestes casos, os artigos serão devolvidos ao(s) autor(es), para os ajustes e reenvio, e aos consultores para nova avaliação. O resultado é comunicado ao(s) autor(es), e os artigos aprovados ficam disponíveis para publicação em ordem de protocolo. Não serão admitidos acréscimos ou modificações após a aprovação.

\section{Declaração de responsabilidade dos autores}

Todas as pessoas responsáveis como autores devem responder pela autoria dos trabaIhos, tendo como justificada a sua participação de forma significativa no trabalho para assumir responsabilidade pública pelo seu conteúdo. Deverão, portanto, assinar a seguinte declaração de autoria e de responsabilidade:
"Declaro que participei de forma significativa na construção e formação deste estudo ou da análise e interpretação dos dados, como também na redação deste texto, tendo, enquanto autor, responsabilidade pública pelo conteúdo deste. Revi a versão final deste trabalho e aprovo para ser submetido à publicação. Declaro que nem o presente trabalho nem outro com conteúdo semelhante de minha autoria foi publicado ou submetido à apreciação do Conselho Editorial de outra publicação."

Artigos com mais de um autor deverão conter uma exposição sobre a contribuição específica de cada um no trabalho. Os autores de cada artigo receberão, após a publicação de seu trabalho, três exemplares da revista em que o seu estudo foi publicado.

\section{Ética em pesquisa}

Com relação às pesquisas iniciadas após janeiro de 1997, nas quais exista a participação de seres humanos nos termos do inciso II. 2 da Resolução 196/ 96 do Conselho Nacional de Saúde ("pesquisa que, individual ou coletivamente, envolva o ser humano de forma direta ou indireta, em sua totalidade ou partes dele, incluindo o manejo de informações ou materiais"), sempre que pertinente, deve ser declarado no texto que o trabalho foi aprovado pelo Comitê de Ética em Pesquisa em Seres Humanos. 
Os trabalhos devem ser enviados para:

Sociedade Brasileira de Medicina de Família e Co-

munidade - SBMFC

Correspondência

Rua 28 de Setembro, 44 sala 804

Rio de Janeiro - RJ

Cep: 20551-031

Tel/fax: 21 2264-5117

Endereço eletrônico:

rbmfc@sbmfc.org.br 